\title{
La naturaleza en y de un encuentro, Gilles Deleuze
}

\author{
[ The nature in AND of An encounter, Gilles Deleuze ]
}

Sergio Martinez Vilajuana* Universidad de Chile, Chile

RESUMEN: Para proponer una aproximación a Gilles Deleuze, preguntaremos en este trabajo por la naturaleza en y de un encuentro. Para desarrollar esto, buscaremos enfatizar que aquella naturaleza se expone en la relación entre signo y acontecimiento en la medida en que ella expresa el carácter vital de aquella. Si esto es así, lo que tendríamos que considerar es que aquello que nos volvería a dar aquella relación supone la introducción de la forma vacía del tiempo. Esto nos llevará a postular, en cuanto aquella forma no está ahí sino para un excesivo informal, o sea, en cuanto aquella forma abisma el sin fondo del pensamiento, que es en la relación entre arte y pensamiento que se jugaría otra experiencia de aquel en tanto en cuanto volvería un encuentro en y con ella a experimentarse; encuentro que ejemplarme expondría aquella naturaleza.

Palabras Claves: Encuentro; signo; acontecimiento; arte; pensamiento
ABSTRACT: In this work we will propose an approximation to Gilles Deleuze asking for the nature in and of an encounter. For develop this, we will emphasise that that nature it is expose in the relation between sign and event. This because is that relation the who express the vital character of that nature. If this is plausible, what we also have to consider in and of that relation is that what could it give us suppose the introduction of the empty form of time. This will take us to posit, inasmuch as in that form it sink to an abyss the without-ground of thought, that in the relation between arte and thought another kind of experience is given inasmuch as an encounter could be again practice in it. Encounter that could expose extraordinarily the nature of that nature.

KEYWORDS: Encounter; sign; event; art; thought

El eterno retorno está en el origen de las alzas y caídas de intensidad y tiene la intención de conducir a ese origen. Desde el momento en que se concibe como el retorno del poder, a saber, que no es más que una serie de rupturas de equilibrio-, la cuestión que entonces se plantea es saber si, en el pensamiento de Nietzsche, el Retorno no es más que una metáfora de la voluntad de poder.

Pierre Klossowski, Nietzsche y el círculo vicioso

Hay algo en el mundo que fuerza a pensar. Gilles Deleuze, Diferencia y repetición

Y, como dice Nietzsche, el caos y el eterno retorno no son dos cosas distintas. Gilles Deleuze, Diferencia y repetición

* Doctor (C) Filosofía. Mención Estética y Teoría del Arte. Magister en Pensamiento Contemporáneo. Universidad Diego Portales, Chile. Licenciado en Estética. Pontificia Universidad Católica, Chile. 2008. Becario Conicyt 2013-2017. m@ilto: sergiosermar@ug.uchile.cl; sergio.sermar@gmail.com 
¡Cuál es la naturaleza de un encuentro? ¿Cuál naturaleza se expresa en un encuentro? Estas preguntas quizás nos permitan aproximarnos al pensamiento de Gilles Deleuze, considerando en principio lo que el filósofo francés, en 1988, en una entrevista para Magazine littéraire $\mathrm{N}^{\circ} 257$ realizada por Raymond Bellour y François Ewald, declaraba: "Todo cuanto he escrito -al menos así lo espero- ha sido vitalista, y constituye una teoría de los signos y del acontecimiento" (2014, p. 228 (p. 196)) ${ }^{1}$. Recordemos que es en Diferencia y repetición (1968) y Lógica del sentido (1969) donde desarrollará en gran medida el filósofo francés aquella teoría. Y es Diferencia y repetición la obra en que se acentuará y expondrá que la génesis del acto de pensar se halla en un encuentro con algo que conmueve, violenta, fuerza el pensamiento a sentir y pensar. Son varios los pasajes en los que Deleuze expresará aquello: que es solo lo que fuerza a sentir y lo que solo puede ser sentido lo que hace que el pensamiento piense. Como dirá Deleuze,

No es lo dado, sino aquello por lo que lo dado es dado. (...). La sensibilidad, en presencia de lo que sólo puede ser sentido (lo insensible al mismo tiempo), se encuentra ante un límite propio -el signo- y se eleva a un ejercicio trascendente la enésima potencia (2012, p. 216 (p. 182)).

Si el actuar que describe el ejercicio habitual del pensamiento implica la reproducción del sentido común $y$ del buen sentido en tanto en cuanto aquel actuar está precedido por la representación de sí en un entorno que producto de aquel ejercicio se torna un lugar familiar en el que el pensamiento se orienta y reconoce habitualmente, lo que fuerza a pensar resquebraja aquel ejercicio: un encuentro con aquello por lo que lo dado es dado hace de un lugar la experiencia de una extrañeza: de lo inhabitual, en cuanto el pensamiento ante el encuentro con un límite propio es forzado a hacer la experiencia de la diferencia; o sea, lo fuerza un encuentro a hacer aquella experiencia en cuanto se quiebra o se triza o se deforma el marco de la representación y del reconocimiento ${ }^{2}$. Tornándose el pensamiento hacia lo que no puede pensar en tanto solo puede ser sentido como límite, lo que el objeto de un encuentro provoca en el pensamiento: una distorsión que genera un ejercicio trascendente, revelando la naturaleza trascendental de él, implica la pregunta por "quién" se presenta en un encuentro. Pues bien, en este trabajo buscaremos responder a la pregunta por "quién" se expresa en un encuentro $y$ por la naturaleza de un encuentro, pero para ello tendremos que considerar que la naturaleza que lo caracterizaría, que caracterizaría un "quién" y un encuentro, habríamos que concebirla en términos de acontecimiento. En este sentido, creemos que hay que recordar aquella suerte de advertencia y dificultad planteada por Deleuze y Parnet en Diálogos,

Pensar en términos de acontecimiento no es fácil. Tanto más difícil cuanto que el mismo pensamiento se convierte entonces en acontecimiento. Pocos hay, salvo los estoicos y los ingleses, que hayan pensado así. ENTIDAD = ACONTECIMIENTO, da pánico, pero también mucha alegría. Convertirse en una entidad, en un infinitivo, como decía Lovecraft, en la terrible y luminosa historia de Carter: devenir-animal, devenir-molecular, devenir-imperceptible" (2013, p. 76 (p. 81))

Volviendo a aquel extracto de aquella entrevista, en la que la pregunta planteada es en torno a la relación entre filosofía y literatura, cuyo límite en Deleuze puede describirse como poroso, tendremos que considerar que aquel "quién" se expone ejemplarmente en casos en que se llega "a experimentar, a pensar" "un cierto exceso de vida" (2014, p. 228 (p.196)). Ahora bien, ¿qué es lo que hace pensar, experimentar, sentir, aquel exceso? ¿cuál es la naturaleza de aquello? Deleuze dirá que no es otra que la de un signo en tanto en cuanto él es la expresión de un límite en el cual se encuentra el pensamiento; esto es, el signo hace que el pensamiento experimente cada vez que él 
es forzado a pensar su límite propio: lo in-sensible, o sea, una diferencia en intensidad. Pues bien, si debemos atender la relación entre signo y acontecimiento para plantear la pregunta por la naturaleza en y de un encuentro, también habremos de sostener que aquella relación y aquella pregunta en Deleuze se hallarían ejemplarmente expuestas en la experiencia de una obra de arte. Pues el privilegio que le concede a las obras de arte como objetos de un encuentro, se debería al hecho que ellas experimentan con los sentidos: con lo dado, en pocas palabras, hacen sensible aquello por lo que lo dado es dado: hacen sensible fuerzas. Es decir, si las obras de arte tienen un estatuto extraordinario en Deleuze, es porque se trata, como ha afirmado J.Vogel (2003) de un objeto poético o como lo ha afirmado J.L Pardo (2011) de un objeto fantástico, cuya singularidad, es decir, el caso que cada objeto expresa, no hace sino sentir, experimentar, pensar, aquel exceso que hace que la naturaleza de un "quién" se presente. En este sentido, en un encuentro con y ante un objeto que hace sentir y pensar se expresaría un "quién", cuya naturaleza no sería otra que la de un acontecimiento. Dicho de otro modo, si el objeto poético o fantástico es un signo que fuerza a pensar, lo que él implica expone la naturaleza de "quién" siente y piensa en él en cuanto que acontecimiento.

Entonces, para intentar responder aquellas preguntas y exponer aquella relación, también tendremos que considerar que lo que se expresa del pensamiento en aquel encuentro con un objeto fantástico o poético que lo fuerza a sentir y pensar, Diferencia y repetición y Lógica del sentido lo describirá, siguiendo la lectura de D.Lapoujade, bajo el signo, crítico y sintomático, "de un sin fondo y de aquello que lo puebla, singularidades preindividuales e impersonales, intensidades, multiplicidades, diferencias libres o nómadas" (2016, p. 34). Pero, para concebir esto, como lo ha mostrado, por ejemplo, Daniela Voss (2013), es necesario considerar la lectura que Deleuze lleva a cabo de Kant, particularmente, la referida a la forma pura y vacía del tiempo, pues es esta esencial para atender el sin fondo y aquello que lo puebla en tanto es aquella forma del tiempo la que revela que el pensamiento está atravesado por una fisura que expone que aquello que piensa en él, una entidad larvaria, un inconsciente nomádico, no puede ser considerada como idéntico a él y como idéntico a sí mismo (en otras palabras, está afuera de la mediación que implica la noción de representación y de reconocimiento). Esto es lo que Deleuze, por ejemplo, siguiendo a Hölderlin, en Diferencia y repetición, llamará un excesivo informal (2012, p. 149 (122-123)). Noción que expone el carácter vital de aquello que el filósofo francés llamará en Lógica del sentido (2011): campo trascendental (2011, pp. 135-136 (124-125)), que, como ha mostrado F.Zouravichvilli (2006, p. 82), es lo que Deleuze con posterioridad llamará: plano de inmanencia (Deleuze, 2007, pp. 347-351 (359-363), en la medida en que aquella noción podría describirse bajo aquella gran síntesis que Deleuze buscará proponer entre Spinoza y Nietzsche (2014, p. 216 (p. 185)). Ahora bien, en cuanto aquel no vuelve a expresarse sino bajo aquella forma vacía del tiempo, para Deleuze el sin fondo y lo que lo puebla no se distingue del actuar de una línea abstracta; esto porque al mismo tiempo que ella se distingue de aquel, ella adquiere toda su fuerza en tanto más violentamente participa del sin fondo (2012, p. 62 (p. 44)). En pocas palabras, si ella lo modula, y van variando los grados de la modulación a medida que lo expresa, también ella, en cuanto el sin fondo no se distingue de ella, es lo que se experimenta en un encuentro; como dice Deleuze, ella actúa directamente en el alma (2012, p. 62 (p. 44)). Esto es, en la medida en que la línea abstracta expresa el sin fondo lo que se presenta bajo aquella forma del tiempo es lo que hace sentir y pensar: la diferencia. Pues bien, que la naturaleza de aquella línea sea la del tiempo, precisamente, la de la forma vacía y pura del tiempo, implicará considerar que es el tiempo el que ya no está subordinado al movimiento (en su sentido clásico, como traslación, como un movimiento periódico); al contrario, ahora es el movimiento el que está subordinado a aquella forma y ello implica que aquel pueda mostrarse como aberrante. Como dirá Deleuze respecto a la 
forma vacía del tiempo: "forma del cambio más radical, pero la forma del cambio no cambia" (2012, p.146 (p. 120)). Entonces, y solo en tanto aquella forma de tiempo se ha introducido en el pensamiento, si volvemos a aquella entrevista tendremos que considerar que la relación entre vitalismo, signo y acontecimiento expresa la naturaleza en y de un encuentro en tanto en cuanto se expone la experiencia como la de un devenir-otro ${ }^{3}$ (devenir-animal, devenir-molecular, devenir-imperceptible; el despliegue de aquel movimiento como expresión del deseo, como proceso deseante (volveremos a esto)).

\section{Del PENSAMiento Y DE La OBRa de ARTE}

Para preguntar por la naturaleza en y de un encuentro, nos será necesario considerar que la forma vacía del tiempo es la que se ha introducido en la experiencia del pensamiento. Esto es, es ella la que hace de la diferencia una experiencia del pensamiento. Y si consideramos que la diferencia es un monstruo (monstrum), o sea, para Deleuze, "el objeto trascendente de la vitalidad sería un monstruo" (2012, p. 221 (p. 187), también tendremos que concebir que aquello que la mostraría en tanto daría aviso de un exceso de vida podría considerarse como una obra de arte. En cuanto en ella se hace del movimiento que experimenta el pensamiento una experiencia que conmueve la naturaleza en y de él, es una exposición que revela la naturaleza-aberrante de aquel "quién" la que se hallaría en el objeto fantástico o poético que fuerza a sentirla y pensarla. Si la naturaleza se revela como un movimiento aberrante, esencialmente como un sin fondo, accidental, contingente, en cuya consistencia está introducido el azar, tendría que tornarse necesario un retorno o repetición de aquella experiencia de la diferencia en tanto lo que se experimentaría una vez no podría cada vez afirmarse sin el todas las veces que buscaría afirmar el retorno o la repetición (répétition) de aquella. Para Deleuze, citamos de Lógica del sentido,

afirmar todo el azar, hacer del azar un objeto de afirmación, sólo el pensamiento puede hacerlo [cursivas de G.D]. Y si se ensaya jugar a este juego fuera del pensamiento, no ocurre nada, y si se intenta producir otro resultado que no sea la obra de arte, nada se produce. (...). Este juego que sólo está en el pensamiento, y que no tiene otro resultado que la obra de arte, es también lo que hace que el pensamiento y el arte sean reales y trastornen la realidad, la moralidad y la economía del mundo. (2011, p. 91 (p. 76))

Esto es, si consideramos que es la relación entre pensamiento y obra de arte la que permite atender la naturaleza en y de un encuentro, es porque en aquella relación volvería a darse lo que no podría ni reconocerse ni representarse bajo el ejercicio habitual del pensamiento al mismo tiempo que restaría como aquello inhabitual, extraño, excesivo, que fuerza a sentir y pensar. $\mathrm{Si}$, en los términos de Diferencia y repetición, lo que "no puede ser sino sentido define el ejercicio trascendente de la sensibilidad, ya que da a sentir, y por eso despierta la memoria y fuerza el pensamiento" (2012, p. 354 (p. 305)), también ello puede ser una vez más experimentado solo bajo la experiencia de "una distorsión de los sentidos" (2012, p. 354 (p. 305)). Por otro lado, es necesario considerar que la introducción de la forma vacía del tiempo es determinante para atender que lo que el pensamiento piensa no es pensable en la medida en que lo que lo hace pensar no es ni representable ni reconocible en y por el ejercicio que le definiría habitualmente; de ahí que aquella forma implique una fisura en el pensamiento. Si, como dirá Deleuze,

Entonces el carácter desgarrador de la intensidad, por más débil que sea su grado, le restituye su verdadero sentido; no se trata de una anticipación de la percepción, 
sino del límite de la sensibilidad desde el punto de vista de un ejercicio trascendente" (2012, pp. 354-355 (p. 305)).

Es el signo que fuerza a pensar el de una intensidad cuya composición altera la naturaleza del pensamiento, pero es desde el punto de vista de un ejercicio trascendente que una experiencia de aquella diferencia en intensidad solo puede experimentarse bajo la introducción de aquella forma del tiempo en tanto bajo esta forma vuelve lo que solo puede ser sentido (2012, p. 149 (122-123)). Es decir, para poder afirmar que la naturaleza en y de un encuentro se presenta ejemplarmente en un objeto poético o fantástico a experimentar, es necesario considerar que aquella forma del tiempo ha sido introducida en aquel objeto en cuanto lo que se compondría en él conmovería el ejercicio habitual del pensamiento. En un encuentro con un objeto poético o fantástico actuaría aquella forma en el pensamiento, y esto debería llevarnos a concebir que lo que hace experimentar la toma de consistencia de un sin fondo y aquello que lo compone es el actuar directo de una línea abstracta que se daría a sentir en la obra que es un objeto poético o fantástico en cuanto se expresaría un movimiento que en tanto está subordinado al tiempo no volvería sino a expresarse en la relación entre obra de arte y pensamiento. En otros términos, la forma vacía del tiempo, cuyo orden simbólico lo expone una cesura, que diferencia el antes y el después y que es precisamente la del instante en el que el pensamiento experimenta la fisura por la que se expresa un otro en él, decíamos, no está ahí sino para un excesivo informal que tomaría consistencia como un hecho de sensación en una obra de arte; y para esto es necesario que el tiempo actúe en ella, es decir, que una cesura se exprese en ella (el caso ejemplar: Hamlet). Lo que presentaría una obra de arte para el pensamiento demandaría aquel ejercicio de distorsión de los sentidos en la medida en que aquella ha devenido para Deleuze "«experiencia», empirismo trascendental o ciencia de lo sensible" (2012, p. 101 (p. 79)). No es otro el caso en Deleuze cuando hace su propia experiencia en y con obras de artes, sean estas literarias, pictóricas, cinematográficas, en cada caso Deleuze busca extraer un concepto que le sea propio a cada una de ellas (el caso del cine es más complejo, porque para Deleuze el cine ya es filosofía ${ }^{4}$ ). Pero si hay algo que las reúne es el carácter moderno de las mismas, es decir, su abandono del dominio de la representación: el hecho que ellas dan a sentir fuerzas. Ahora bien, no es sino porque en ellas habría de hallarse ejemplarmente la naturaleza en y de un encuentro: pensemos por un momento como una experiencia fuera de quicio en el Ulises de Joyce (2005) (y no es menor la constante referencia en ella a Hamlet de Shakespeare). Pues bien, si el Ulises es un ejemplo para Deleuze es porque, en el decir de Diferencia y repetición, el caos-cosmos que lo explica "“[s]e confunde con la gran obra, que mantiene todas las series complicadas, que afirma y complica todas las series simultáneas" (2012, p. 192 (p. 161)). Que en el transcurso de la novela haya que considerar cada vez una cierta afirmación del azar, en cuanto distintas temporalidades se expresan en las variaciones que implica la experimentación de diversos tipos de enunciados en ella, no se debería sino a que, como dirá Deleuze, en el capítulo “¿Qué es un acontecimiento?” en El Pliegue, "[1] as series divergentes trazan en un mismo mundo caótico senderos siempre bifurcantes, es un « caosmos», como el que aparece en Joyce, pero también en Maurice Leblanc, Borges o Gombrowicz" (1989, pp. 107-108 (p. 111). Esto es, el azar que permite que la novela vaya bifurcándose todas la veces en tanto en cuanto se afirma la divergencia entre la series implica un acontecimiento que hace que el mundo se presente abigarrado, heterogéneo, como "una «polifonía de polifonías»" (1989, p. 108 (p.112)). Y no es sino aquella obra la que vuelve a dar aquel acontecimiento en cuanto la intuición que desarrolla ella misma está impulsada por la experiencia de un caoscosmos. Esto es lo que se expresaría en y de la naturaleza de un encuentro con ella, con el objeto poético o fantástico que es el Ulises de Joyce.

Que la relación entre obra de arte y pensamiento exprese la naturaleza en y de un 
encuentro a través del pasaje que abre la composición de una imagen o de un signo o de una figura o de un ritmo o de una modulación que expondría la naturaleza de aquel "quién”, implicaría considerar que en aquella relación hay una experiencia en juego: la de un exceso de vida que hace que el pensamiento experimente una distorsión de los sentidos, una discordancia que lo fuerza a pensar. En este sentido, tendríamos que considerar que una obra de arte "invoca una virtualidad en la que se sumerge" (Deleuze, 2012, p. 315 (p. 270)) en tanto en cuanto en lo virtual vive aquel "quién", es decir, el sin fondo y aquello que lo puebla. En Diferencia y repetición Deleuze dirá, extrayéndolo de Proust, que "lo virtual no se opone a lo real, sino tan solo a lo actual. Lo virtual posee una realidad plena en tanto es virtual [cursiva de G.D]" (2012, pp. 314-315 (pp. 269-270)), por esto, el transporte (la metáfora) implica la vuelta, el retorno, de una experiencia que no se expresa sino como la del movimiento de lo virtual $^{5}$. Ahora bien, si, en el decir de Nietzsche y la filosofía,

El arte (...) es «estimulante de la voluntad de potencia» [y la voluntad de potencia no es sino equivalente en la lectura de Deleuze a aquel caosmos que la diferencia es exponiéndose y que la experiencia de lo virtual es expresándose (agregado nuestro)], [el arte es] «excitante del querer». (...). [Y] Verdad significa [ahora] efectuación de la potencia, elevación a la mayor potencia. (1996, pp. 144-145 (pp. 116-117))

es porque en y con el arte, en y con aquel objeto fantástico o poético que es la obra de arte, volvería a experimentarse lo que implicaría la naturaleza en y de un encuentro: la exposición de aquello que una experiencia del pensamiento experimentaría en cuanto aquella expresaría la verdad de ella misma: o sea, si ha de volverse la experiencia del pensamiento la del mundo de la voluntad de potencia, es decir, "la de las cantidades intensivas", la "del teatro de toda metamorfosis" (Deleuze, 2012 , p. 360 (p.310)), lo que se extraería de aquel mundo comprometería la afirmación de una heterogeneidad cuya verdad vuelta obra de arte implicaría sentirla y pensarla como tal. Este sería el experimento, la producción de verdad, que el pensamiento haría en y de la obra de arte, pero cada vez singular: de cada obra se extraería un concepto distinto. Como preguntará Nietzsche en La ciencia jovial, “¿Hasta qué punto tolera la verdad hacerse cuerpo [die Einverleibung: la incorporación]? -Esa es la pregunta, ese es el experimento" (1999, §110).

\section{II. ¿EL RETORNO NO ES MÁS QUE UNA METÁFORA DE LA VOLUNTAD DE PODER (VOLONTÉ DE PUISSANCE)?}

Una obra de arte expresaría una elevación a la mayor potencia. Pero, que exponga un problema para el pensamiento en cuanto implica una parte virtual (real $e$ ideal) que vuelve a experimentarse encontrándonos en y con ella, hace de aquel juego que es el pensamiento, y cuyo resultado no es sino una obra de arte, un asunto que, dicho en términos kantianos, no puede considerarse bajo el principio de las anticipaciones de la percepción en la medida en que Deleuze desea considerar que la génesis del pensar, producto de la contingencia de un encuentro, no puede atenderse bajo el primado del entendimiento en cuanto, dicho nuevamente en kantiano, la génesis de las facultades hallaría su principio analítico en la relación entre la imaginación y la razón. Esto es, prescindiendo del entendimiento lo que fuerza a pensar no lo describe sino la experiencia de lo sublime y no de lo bello: en la lectura de Deleuze de la tercera crítica de Kant, en la que Kant elaboraría una génesis de las facultades, es la experiencia desgarradora de una disarmonía la que fuerza el pensamiento a pensar (2005, pp. 85-89 (pp. 89-93) $)^{6}$. En este sentido, y otra vez en kantiano, también hay que considerar que el ejercicio habitual del pensamiento, el del reconocimiento y de la 
representación, se halla conmovido en y por la experiencia de lo sublime en tanto expresa un ejercicio disarmónico entre las facultades; el pensamiento prescinde del entendimiento y se origina en la relación entre la imaginación y la razón, cuya relación en Deleuze la generaría un encuentro con lo que hace que lo dado sea dado: de ahí que la intensidad sea expresión de un límite y no de una anticipación de la percepción, esto es, la experiencia de un límite que genera una experiencia de lo trascendental en la medida en que se experimenta el límite, el grado $=0$, una diferencia en intensidad (volveremos a esto). Ahora bien, como dirá Deleuze,

Y no es seguro que únicamente el sueño de la Razón engendre monstruos. También lo hace la vigilia, el insomnio del pensamiento, pues el pensamiento es ese momento en que la determinación se hace una, a fuerza de sostener una relación unilateral y precisa con lo indeterminado (2012, p. 62 (p.44))

Pues bien, si el objeto trascendente del vitalismo sería el monstruo (monstrum), también tenemos que considerar que en la relación entre obra de arte y pensamiento lo que hace que vuelva a presentarse la diferencia no es sino una experiencia del tiempo, y es la diferencia en cuanto sin fondo y aquello que lo puebla lo que se expresaría en y con ella. Si la determinación se hace una es porque el pensamiento hace la experiencia de la diferencia, y para volver hacer la experiencia de la diferencia le es necesario aquello que lo fuerce a sentirla como tal. En este sentido, si el arte es estimulante de la voluntad de potencia es porque eleva a esta a su mayor potencia, es decir, hace sentir las diferencias en intensidad en el objeto poético o fantástico que es una obra. Entonces, más allá del tono kantiano porque es necesario considerar que la naturaleza en y de un encuentro no puede concebirse en analogía a la relación entre sujeto y objeto (y más allá que en las analíticas de la crítica de la facultad de juzgar no se trate del objeto sino de la experiencia del sujeto), en cuanto esta relación en Deleuze es propia al movimiento que describe lo actual y no lo virtual (Deleuze, 1996, pp. 179-185), hay que intentar atender el acontecimiento que se expresa en un encuentro como la experiencia de una disonancia que hace que el pensamiento experimente la diferencia. Diferencia que en cada caso en una obra se elaboraría como una experiencia de lo sensible en tanto en cuanto ella expresaría un exceso de vida que tomaría consistencia singularmente en ella. O, como dirá Deleuze en Diferencia y repetición,

En el teatro de la repetición (Dans le théâtre de la répétition), se experimentan fuerzas puras, los trazos dinámicos en el espacio que actúan sobre el espíritu sin intermediarios, y que lo unen directamente a la naturaleza y a la historia, un lenguaje que habla antes que las palabras, los gestos que se elaboran antes que los cuerpos organizados, las máscaras antes que los rostros, espectros y fantasmas antes que los personajes - todo el aparato de la repetición como «potencia terrible» (2012, pp. 34-35 (pp. 19))

Pues bien, tenemos que decir que aquel "antes que" busca dar cuenta de lo que afuera del marco de la representación y del reconocimiento es inmanente en él. En otras palabras, lo que busca expresar Deleuze bajo la noción de teatro de la repetición es lo que le da consistencia al mundo, esto es, el teatro de toda metamorfosis, o sea: relaciones de fuerzas que, como dirá Zouravichvilli, "consisten, en el sentido fuerte, en una imbricación de afectos variables que son los acontecimientos de la Naturaleza" (2004, p. 129). Como hemos intentado decir, si el transporte (la metáfora) implica el retorno de una experiencia del pensamiento en la que se expresa un movimiento de lo virtual, lo que habríamos de considerar como la naturaleza en y de un encuentro implicaría aquellos acontecimientos de la Naturaleza (= el mundo como voluntad de potencia) en tanto se experimentarían alzas y caídas de intensidad. $\mathrm{Si}$, en términos de Zouravichvilli, "[u]n cuerpo no es una cosa, una sustancia, no tiene realmente contornos, no existe sino en tanto afecta y es afectado, en tanto que es sentido y siente" 
(2004, p. 129), lo que aquel implica es una virtualidad en la que persiste aquel exceso de vida que es el de la naturaleza de la diferencia, la cual no puede experimentarse sino en cuanto acontecimiento. En este sentido, el teatro de la repetición puede ser aprendido como una noción con la cual Deleuze busca dar cuenta que para experimentar aquello por lo que lo dado es dado no es sino necesario un ensayo (répétition). La dificultad, entonces, en la que nos hallamos, es podría decirse descriptiva en la medida en que buscamos atender la naturaleza en y de un encuentro. Esto es, en cuanto aquella naturaleza expone el afuera inmanente que fuerza a sentir y pensar, lo que habría de interesarnos es el proceso o la génesis que hace que el pensamiento experimente una fractura, $y$ viceversa: la fractura que hace que el pensamiento experimente una relación de fuerzas que lo fuerce a pensar. Como veíamos, si en la lectura de Deleuze de Kant, la cual también la extenderá en Diferencia y repetición a través de la interpretación que propondrá de la doctrina de las facultades, es lo sublime la experiencia en la que se halla la génesis del pensamiento, lo que ahora habríamos de intentar considerar es que lo que se expondría: lo que busca describir Deleuze a través de conceptos como singularidades preindividuales e impersonales, intensidades, multiplicidades, diferencias libres o nómadas, es un mundo, como dirá en Diferencia y repetición, cuya "secreta coherencia no se plantea más que excluyendo mi propia coherencia, mi propia identidad, la del yo [moi], la del mundo y la de Dios” (2012, p. 148 (p.122)). En pocas palabras, aquella secreta coherencia es la que expondría la naturaleza en y de un encuentro. Y el esfuerzo de Deleuze radicaría en intentar describirla. Ahora bien, si hemos intentado plantear que la exposición de aquella secreta coherencia, que es la de un exceso de vida, vuelve a experimentarse en una obra de arte en tanto es ella la que eleva en su mayor potencia la voluntad de potencia, también habremos de considerar que el acontecimiento que viene se expresa en la experiencia del retorno, es decir, bajo la forma vacía del tiempo se expresa que lo que una y otra vez vuelve no puede sino experimentarse en y por una fractura, una cesura, que presenta aquello que el ejercicio habitual del pensamiento no puede reconocer, no puede representar; de ahí que la fisura del pensamiento, la cual surge con la cesura, haga que él enfrente el sin fondo que expone el afuera de él. Que haya que violentar el pensamiento para romper con el ejercicio que le caracteriza habitualmente es una necesidad que en Deleuze podría concebirse como un imperativo en tanto en cuanto la experiencia se presenta para una perspectiva vitalista como monstruosa. En este sentido, es la naturaleza de un encuentro la que abre lo que en un acontecimiento está en juego: un devenir-otro. Y es en Mil Mesetas que Deleuze-Guattari propondrán una suerte de definición del devenir,

Devenir, es, a partir de las formas que se tiene, del sujeto que se es, de los órganos que se posee o de las funciones que se desempeña, extraer partículas, entre las cuales se instauran relaciones de movimiento y reposo, de velocidad y lentitud, lo más próximas a lo que se está deviniendo, y gracias a las cuales se deviene. Es en este sentido que el devenir es el proceso del deseo", (2010, p. 275 (p.334).

Que la naturaleza en y de un encuentro se experimente como un proceso deseante, implica considerar que la experiencia del pensamiento, en la fractura, en la cesura, se expresa como un devenir. No es que se desee experimentar aquel proceso, al modo de una elección, más bien se experimenta el proceso del deseo en un encuentro, y lo que a Deleuze le interesa es dar cuenta de aquello para hacer posible un ensayo (répétition) de ello. Para decirlo con otras palabras, en términos de Mil mesetas, la

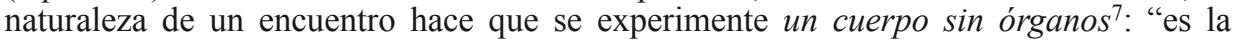
materia intensa y no formada, no estratificada, la matriz intensiva, la intensidad $=\mathrm{O}$. (...) Producción de lo real como magnitud intensiva a partir de cero" (2010, p. 158 (p. 189)). Brevemente, como dirá Zouravichvilli, "si CsO no es el cuerpo vivido sino su límite, es porque remite a una potencia insoportable como tal, la de un deseo siempre en marcha y que jamás se detendría en formas" (2006, p. 40). Si volvemos entonces a 
plantearnos la naturaleza en y de un encuentro, el acontecimiento que viene es el de una intensidad cuya magnitud se experimenta como límite en tanto en cuanto vuelve a dar con aquello que excluye mi propia coherencia en cuanto sujeto de representación y de reconocimiento. Son los acontecimientos de la Naturaleza (= sin fondo y aquello que lo puebla $=$ voluntad de potencia $=\mathrm{CsO}$ ) los que se experimentarían en un encuentro en el que se expondría el proceso del deseo, y serían las obras de artes (objetos poético o fantásticos) en cuanto que experiencias las que expresarían aquella Naturaleza en tanto la elevarían a mayor potencia. Si, en el decir de Diferencia y repetición, "ella debe ante todo ser sentida como aquello que permite que lo diverso pueda ser sentido. Y debe ser pensada como lo que crea lo diverso. [...]. Y henos forzados de sentir y de pensar la diferencia" (2012, p. 340 (pp. 292-293)), también tendríamos que considerar cuál es la naturaleza del retorno, pues si se trata de una metáfora lo que habríamos de considerar en la relación entre arte y pensamiento no sería sino aquello que en la relación hace de transporte.

Al menos, por lo que se desprende de ¿Qué es la filosofía? (2009) la conjugación entre afectos, perceptos y conceptos expresarían la naturaleza de un pensamiento cuya génesis y devenir se debería a un encuentro entre arte y filosofía. Pero si precisamente la repetición (répétition) se revela como una potencia terrible, lo que la naturaleza en y de encuentro expresa habríamos de intentarlo concebir bajo lo que Deleuze (y Guattari) llama una línea de fuga (2010, pp. 232-234 (pp. 279-283). Esto es, ¿lo que en el límite se expone de la naturaleza en y de un encuentro, aquel exceso de vida que se expresa en una obra de arte (y así es el caso de Ulises de Joyce, pero este no es el único caso), cuyo objeto trascendente para el vitalismo no es sino el monstruo (monstrum), acaso no se muestra como el límite entre vida y muerte, es decir, como aquel límite en que se muestra la naturaleza de lo viviente, más allá de toda organización de ella? Por un lado, haría falta otro trabajo o quizá todo un programa de investigación para intentar desarrollar esta pregunta, pero lo que tendríamos que dejar por ahora enunciado es que aquello que podría definir lo viviente desde una perspectiva empírico-trascendental y que expondría la bestialidad propiamente humana no sería sino lo que Deleuze en Diferencia y repetición llamará la bêtise (2012, pp. 231-234 (pp. 196-198)). Por otro lado, la naturaleza de lo viviente, en un encuentro con lo que hace sentir y pensar en ella, no se agota en el hecho de forzarnos a pensar en la bêtise, sino, más bien, en cuanto que inagotable o imponderable o inconmesurable el proceso deseante, ella, aquella naturaleza, no se distingue del actuar de una línea abstracta. Si entonces esta vuelve a encontrarse o a exponerse en la relación entre obra de arte y pensamiento, considerando que, con Deleuze y Guattari, “[q]uizá esto es lo propio del arte, pasar por lo finito para volver a encontrar (retrouver), volver a dar (redonner) lo infinito" (2009, p. 199 (p. 186)), es ella, una línea abstracta, la que podría llevarnos a pensar que el objeto trascendente del vitalismo, el monstruo, no está sino afecto de devenir-otro. Es un monstruo en cuanto puede ser descrito como un movimiento aberrante, pero también es expresión de la naturaleza en tanto en cuanto expresa la naturaleza del devenir. Es decir, si concebimos que el acontecimiento es equivalente a lo que se expresa bajo la forma vacía del tiempo en tanto es ella simbólicamente considerada como un orden en el que el antes y el después lo divide una cesura, aquella descripción implica en su exposición un movimiento: se muestra el sin fondo y aquello que lo puebla, y aquella forma que lo muestra es la del eterno retorno en cuanto vuelve a experimentarse diferencias en intensidad en y por el traslado o pasaje que aquella forma expresa. El objeto que fuerza a sentir y pensar puede volver a experimentarse si lo que de aquel se repite no es objeto del dominio de la representación en la medida en que, para decirlo en los términos de Diferencia y repetición, solo una vez se repite en cuanto diferencia en sí misma. Ahora bien, de aquí que la afirmación del eterno retorno sea relevante para Deleuze y que no pueda ser considerada sino como un ensayo (répétition) en el que está en juego un traslado o un pasaje de lo finito a lo infinito; es 
decir, Deleuze al concebir que la relación entre obra de arte y pensamiento hace del una vez el cada vez de todas veces, está al mismo tiempo considerando que lo que se diferencia puede volver a darse en aquella relación en tanto se buscaría afirmar todas las diferencias en las repeticiones bajo aquella síntesis que expresa el eterno retorno y la experiencia que él implica (Deleuze, 2012, pp. 151-154 (125-128)). En otros términos, para volver al caso del Ulises de Joyce, si las variaciones que se presentan son objetos de afirmación en cuanto se expresan como diferencias de grado de una naturaleza que solo se divide si cambia de naturaleza, en la obra de Joyce, siguiendo la lectura de Deleuze, las series que expresan aquellas diferencias las va generando el azar en tanto afirma las distintas dimensiones del tiempo que se presentan durante un día; complica aquellas variaciones y sus relaciones en términos de series simultáneas y divergentes. En pocas palabras, lo que exponen y lo que las expone es un caosmos que expresa un mundo in-finitamente en variación que no vuelve sino en y con aquella obra, que ella eleva su enésima potencia.

Pues bien, y estamos sobrepasando los límites de este trabajo, lo que la naturaleza en y de un encuentro con una obra de arte podría hacer experimentar, y que al mismo tiempo habría de llevarnos a concebir que el límite de lo viviente es inorgánico, podría llegar concebirse como un devenir-música (Deleuze y Guattari, 2010, pp. 298-307 (pp. 367-380)). Si aquel devenir es equivalente al actuar de una línea abstracta, en cuanto la potencia del sin-fondo se revela en aquel devenir radicalmente fuera de toda proposición, ello implicaría considerar que la naturaleza del devenir no la expondría sino una composición que la conjugaría una relación entre líneas y movimientos (Deleuze y Guattari, 2010, p. 353 (p. 433)) en la medida en que se experimenta en aquel devenir una línea de fuga. Si hemos entonces intentado preguntar por la naturaleza en y de un encuentro en este trabajo, considerando que ejemplarmente ella vuelve a darse o ensayarse en la relación entre obra de arte y pensamiento, lo que de aquella se expresaría sería el afuera que en la relación entre signo y acontecimiento se presenta, en cuanto diferencia, o sea, un devenir-otro en tanto que vuelve a retornar. Esto es, todas las veces que el hecho en cada caso singular de la relación entre signo y acontecimiento se presenta, volvería cada vez a expresarse el devenir-otro del objeto del vitalismo en un encuentro en y con lo que lo fuerza a sentir y pensar ${ }^{8}$.

\section{Bibliografía}

CANAVERA, J. "Notas sobre la crítica de la imagen dogmática en la obra de Gilles Deleuze", Revista de filosofía. Vol. 40 Núm. 2, pp. 83-108, 2015

CÁRDENAS, J. D. "La organicidad: sobre los presupuestos de la imagen dogmática del pensamiento según Gilles Deleuze". Ideas y Valores 63.156, pp. 7-32, 2014.

DeleuZE, G. Conversaciones., Trad. Pardo, J. L., Madrid: Pre-Textos, 2014; Pourparlers 1972-1990. Paris: Les Éditions de Minuit, 1990

DELEUZE, G. y PARNET, C. Diálogos. Trad. Vázquez Pérez, J., Valencia: Pre-textos, 2013; Dialogues. Paris: Flammarion, 1996.

DELEUZE, G. Diferencia y Repetición. trad. Delpy, S. y Beccacece, H. Buenos Aires: Amorrortu, 2012; Différence et Répétition. Paris: Presses Universitaires de France, 2011.

DELEUZE, G. Lógica del sentido, Trad. (texto) Morey, M., y (apéndice) Molina, V. Madrid: Paidós, 2011; Logique du sens. Paris: Les Éditions de Minuit, 1982.

DELEUZE, G. y GUATTARI, F. Mil mesetas. Capitalismo y esquizofrenia. Trad. Vásquez Pérez, J. con colaboración de Larraceleta, U. Valencia: Pre-Textos, 2010; Mille Plateaux. Capitalisme et Schizophrénie. Paris: Les Éditions de Minuit, 1980.

DELEUZE, G. La inmanencia: una vida.... En DELEUZE, G. Dos regímenes de locos. Textos y entrevistas (1975-1995). Trad. Pardo, José Luis. Valencia: Pre-Textos, pp. 347-351, 2007; L'immanence: une vie... En Deux Régimes de fous. Textes et entretiens 1975-1995. Édition préparée par David Lapoujade. Paris: Les Éditions de Minuit, pp. 359-363, 2003. 
DELEUZE, G. La idea de génesis en la estética de Kant. En DELEUZE, G. La Isla Desierta y otros textos. Textos y entrevistas (1953-1974). trad. Pardo, José Luis. Valencia: PreTextos, pp. 77-95, 2005; L'Idée de genèse dans l'esthetique de Kant. En L'Île Déserte, Textes et entretiens 1953-1974. Édition préparée par David Lapoujade. Paris: Les Éditions de Minuit, , pp. 79-101, 2002.

DELEUZE, G. Nietzsche y la filosofia. Trad. Artal, C., Barcelona: Editorial Anagrama, 2002; Nietzsche et la philosophie. Paris: Presses Universitaires de France, 1983.

DELEUZE, G. y GUATTARI, F. ¿Qué es la filosofía? Trad. Kauf, T., Barcelona: Editorial Anagrama, 2009; Qu'est-ce que la philosophie? Paris: Les Éditions de Minuit, 2005.

DELEUZE, G. "L'actuel et le virtual". En DELEUZE, G. y PARNET, C. Dialogues. Paris: Flammarion. pp. 179-185, 1996.

DELEUZE, G. El pliegue. Leibniz y el Barroco Trad. Vásquez Pérez, J. y Larraceleta, U. Barcelona: Ediciones Paidós, 1989; Le pli. Leibniz et le Baroque. Paris: Les Éditions de Minuit, 1988.

JOYCE, J. Ulises. Trad. Salas Subirat, J. Buenos Aires: Losada, 2005.

KLOSSOWSKI, P. Nietzsche y el círculo vicioso. Trad. Herrera, I., Madrid: Arena Libros, 2004.

LAPOUJADE, D. Deleuze, los movimientos aberrantes. Trad. Ires, P. Buenos Aires: Cactus, 2016.

MARRATI, P. Gilles Deleuze, cinéma et philosophie. Paris: Presses Universitaires de France, 2002.

MONTEBELLO, P. Deleuze, philosophie et et cinéma. Paris: Librairie Philosophique J. Vrin, 2008.

NIETZSCHE, F. La ciencia jovial. Trad. Jara, J., Caracas: Monte Ávila Editores Latinoamérica, 1999.

PARDO, J. L. El cuerpo sin órganos. Presentación de Gilles Deleuze. Madrid: Pre-textos, 2011.

VOGL, J. Was ist ein Ereignis? en ZKM. Symposien Gilles Deleuze und die Künste. Wiederholung und Differenz. Festival: 24. - 26.10.2003. Ausstellung: 24.10. 07.12.2003. http://on1.zkm.de/zkm/stories/storyReader\$4048\#eins. Consultada el 29 de junio 2016.

VOSS, D. Deleuze's Third Synthesis of Time. Deleuze Studies, 7.2, pp. 194-216, 2013

ZOURAVICHVILI, F. Deleuze. Una filosofía del acontecimiento. Trad. Agoff, Irene. Buenos Aires: Amorrortu, 2004.

ZOURAVICHVILI, F. El vocabulario de Deleuze. Trad. Goldstein, V. Buenos Aires: Editorial Atuel, 2007.

\section{Notas}

1 Para las obras citadas de Deleuze en este trabajo, irán en primer lugar los datos de la traducción al español y entre paréntesis el número de página de la edición francesa. La única excepción es el texto "L'actuel et le virtual" que no se encuentra en la traducción al español de Diálogos.

2 Respecto a esta imagen del pensamiento como ejercicio de reconocimiento y representación, ver: Cárdenas (2014) y Canavera (2015).

3 Esto es lo que desarrollaran Deleuze y Guattari extensamente en el capítulo 10 de Mil Mesetas, Meseta titulada: "1730. Devenir-intenso, devenir-animal, devenir-imperceptible..."

4 Para esto, ver Marrati (2002) y Montebello (2008).

5 Respecto al movimiento que caracteriza a lo virtual, Deleuze (1996, pp. 179-185).

6 Respecto a esta lectura, hay un amplia bibliografía, una puesta al día de ella puede encontrarse en Autor (2017)

7 "De todas maneras tienes uno (o varios), no tanto porque preexista o venga dado hecho -aunque en cierto sentido preexiste-, sino porque de todas maneras haces uno, no puedes desear sin hacer uno- te espera, es un ejercicio, una experimentación inevitable, ya hecha en el momento en que la emprendes, no hecha en tanto que no la emprendes. No es 
tranquilizador, puesto que puedes fallarlo. $\mathrm{O}$ bien puede ser terrorífico, conducirte a la muerte. Es no-deseo tanto como deseo. De ningún modo es una noción, un concepto, más bien es una práctica, un conjunto de prácticas. El Cuerpo sin Órganos no hay quien lo consiga, no se puede conseguir, nuca se acaba de acceder a él, es un límite" (Deleuze y Guattari, 2010, pp. 155-156 (pp. 185-186)).

$868 \mathrm{Y}$, al mismo tiempo, habría que considerar que si el objeto trascendente del vitalismo es el monstruo $y$ el objeto trascendente de la sociabilidad sería la anarquía (2012, p. 221), podría preguntarse si acaso lo monstruoso en cuanto devenir no consista sino en un devenir-infancia. 